\title{
RESPOSTA IN VITRO E SUSCETIBILIDADE AO AGROBACTERIUM DE DUAS CULTIVARES DE STYLOSANTHES GUIANENSIS ${ }^{1}$
}

\author{
LUCIA VIEIRA HOFFMANN² e MARIA LUCIA CARNEIRO VIEIRA ${ }^{3}$
}

\begin{abstract}
RESUMO - As cultivares Bandeirantes e Mineirão de Stylosanthes guianensis (Leguminosae) foram avaliadas quanto à capacidade de formação de brotos adventícios in vitro e quanto à suscetibilidade ao Agrobacterium. Para obter regeneração, foram utilizados vários tipos de explantes, e o meio basal MS foi suplementado com diferentes concentrações de ácido naftalenoacético (NAA) e 6-benzilanimopurina (BAP). Observou-se regeneração de brotos a partir de explantes cotiledonares e hipocotiledonares, nas duas cultivares. O Stylosanthes mostrou-se suscetível ao Agrobacterium selvagem, pois a formação de tumores foi induzida. Expressão transiente do gene uidA foi observada em tecidos infectados de Stylosanthes. Experimentos sobre a ação dos antibióticos cefotaxima e tetraciclina, usados em ensaios de transformação para eliminação do Agrobacterium, mostraram que a cefotaxima $\left(250 \mu \mathrm{g} \mathrm{mL}^{-1}\right)$ tende a reduzir a regeneração de brotos em explantes da cv. Bandeirantes.
\end{abstract}

Termos para indexação: cultura de tecidos, leguminosa forrageira, transformação de plantas, expressão transiente.

\section{IN VITRO RESPONSE AND AGROBACTERIUM SUSCEPTIBILITY OF TWO CULTIVARS OF STYLOSANTHES GUIANENSIS}

\begin{abstract}
Two Stylosanthes guianensis (Leguminosae) cultivars, Bandeirantes and Mineirão, were evaluated for their ability to form adventitious shoots in vitro and Agrobacterium susceptibility. To obtain regeneration, several explant sources were used and MS basal medium was supplemented with different concentrations of NAA and BAP. Shoot regeneration occurred in both cultivars from cotyledon and hypocotyl-derived tissues. Stylosanthes was susceptible to wild Agrobacterium strains, since tumor formation was induced. Transient expression of the uidA gene was observed on infected Stylosanthes tissues. Experiments on the effect of the antibiotic cefotaxime and tetracycline, used in transformation assays to Agrobacterium elimination, showed that cefotaxime $\left(250 \mu \mathrm{g} \mathrm{mL}^{-1}\right)$ has a tendency to reduce shoot regeneration in $\mathrm{cv}$. Bandeirantes explants.
\end{abstract}

Index terms: tissue culture, forage legume, plant transformation, transient expression.

\section{INTRODUÇÃO}

O gênero Stylosanthes (Leguminosae-Papilionoidea) é nativo do Brasil, onde mostra ampla distribuição geográfica e extensa variabilidade genética. Como

\footnotetext{
${ }^{1}$ Aceito para publicação em 27 de abril de 1999.

${ }^{2}$ Eng. Agrôn., M.Sc., Dep. de Ciência e Tecnologia Agroindustrial, Escola Superior de Agricultura "Luiz de Queiroz" (ESALQ), Universidade de São Paulo (USP), Caixa Postal 9, CEP 13400-970 Piracicaba, SP.

${ }^{3}$ Biól., Dra, Livre Docente, Dep. de Genética, ESALQ-USP.

E-mail: mlcvieir@carpa.ciagri.usp.br
}

planta forrageira, foi inicialmente introduzida na Austrália, onde se deu o desenvolvimento das primeiras cultivares de Stylosanthes guianensis e S. humilis (Hopkinson \& Walker, 1984). Na América do Sul, o Stylosanthes guianensis é recomendado por ser adaptado a solos ácidos, deficientes em P e com elevados teores de Al. Segundo relatos de Ghisi et al. (1993) é também resistente à seca e sensível a baixas temperaturas.

Cultivares de $S$. guianensis têm sido selecionadas pela Embrapa, visando obter populações tolerantes à antracnose, principal limitação para plantio das cultivares australianas quando introduzidas no Brasil (Embrapa, 1993). 
Uma das estratégias para a obtenção de plantas resistentes a patógenos ou com maior qualidade protéica é via transferência de genes exógenos, seguida da regeneração de brotos a partir dos tecidos transformados. A transformação de plantas vem sendo obtida em número crescente de espécies, e o método mais usado é o que utiliza o Agrobacterium como vetor de transferência de genes. Este processo é dependente da interação Agrobacterium-hospedeiro vegetal, da remoção da bactéria por um antibiótico e, ainda, do uso de marcadores seletivos (Barros et al., 1997). Antibióticos como cefotaxima e carbenicilina são utilizados para eliminação da bactéria em ensaios de transformação. Lavagens dos explantes infectados com tetraciclina são auxiliares nessa desinfecção. Segundo Sarma et al. (1995), estes podem, ocasionalmente, interferir na resposta in vitro dos explantes vegetais.

No caso do Stylosanthes, vários protocolos têm sido definidos visando à obtenção de brotos a partir do cultivo de diferentes explantes (Meijer \& Szabados, 1991). A regeneração ocorre geralmente via calo (Silva, 1991; Dornelas et al., 1992), o que é indesejado, uma vez que este processo pode induzir o aparecimento de variantes somaclonais.

Os objetivos deste trabalho foram: 1. desenvolver protocolos para obter a regeneração de brotos adventícios, sem passagem por fase conspícua de calo, em duas cultivares de Stylosanthes guianensis; 2. verificar sua suscetibilidade ao Agrobacterium, e 3. caracterizar o efeito dos antibióticos cefotaxima e tetraciclina sobre a cultura de tecidos de S. guianensis.

\section{MATERIAL E MÉTODOS}

\section{Material vegetal}

As cultivares de Stylosanthes guianensis utilizadas foram a Mineirão e a Bandeirantes, ambas desenvolvidas pela Embrapa-Centro de Pesquisa Agropecuária dos Cerrados (CPAC), que forneceu sementes para a realização deste estudo (Embrapa, 1993).

\section{Obtenção dos explantes}

Sementes da cv. Bandeirantes foram escarificadas por temperatura, mediante embebição em água a $80^{\circ} \mathrm{C}$, por dez minutos. As sementes da cv. Mineirão foram escarificadas por temperatura ou manualmente (com pinça). Para esterilização, foram embebidas em etanol $70 \%(\mathrm{v} / \mathrm{v})$ por 40 segundos, e a seguir, em solução de $\mathrm{NaOCl} 2 \%(\mathrm{v} / \mathrm{v})$ por 8 minutos, sendo então lavadas quatro vezes em água destilada, deionizada e autoclavada. A germinação das sementes da cv. Bandeirantes ocorreu em meio MS (Murashige \& Skoog, 1962) contendo a metade da concentração original de sais e compostos orgânicos (MS/2). As sementes da cv. Mineirão, escarificadas manualmente, germinaram em meio MS/6, e as escarificadas por temperatura, em MS/2. A germinação se deu seis dias após a inoculação.

Foram utilizados explantes derivados de hipocótilo, cotilédone, raiz e folha. Os explantes hipocotiledonares e cotiledonares foram excisados aos 16 dias após a infecção das sementes, enquanto os de raiz e folíolo, após 30 dias. Os explantes cotiledonares sofreram um corte transversal na sua base, enquanto os de folha, na base e na ponta. Ambos foram colocados com a superfície abaxial em contato com o meio de cultura. Os explantes de raiz derivaram de segmentos de cerca de $1 \mathrm{~cm}$ da raiz principal. Os explantes hipocotiledonares, denominados superior e inferior (segundo a sua orientação no seedling), foram obtidos cortando-se os hipocótilos ao meio, gerando segmentos de $1 \mathrm{~cm}$.

\section{Condições de cultivo e avaliação da resposta in vitro}

Foram usadas, para cada um dos cinco tipos de explante, das duas cultivares, 20 combinações dos fitorreguladores BAP (6-benzilaminopurina) e NAA (ácido naftalenoacético): $0,0,0,1,0,5$ e $2,0 \mathrm{mg} \mathrm{L}^{-1}$ de NAA x 0,0 , $0,1,0,5,1,0$ e 2,0 $\mathrm{mg} \mathrm{L}^{-1}$ de BAP. Após adição dos reguladores de crescimento, o $\mathrm{pH}$ do meio foi corrigido para 5,8. Foram distribuídos $25 \mathrm{~mL}$ de meio em frascos de $120 \mathrm{~mL}$ de capacidade, os quais foram autoclavados a $120^{\circ} \mathrm{C}$, durante 20 minutos. Inocularam-se três explantes/frasco, os quais foram mantidos sob $30 \mu \mathrm{E} \mathrm{m}^{2} \mathrm{~s}^{-1}$ de intensidade luminosa, à temperatura de $28 \pm 2^{\circ} \mathrm{C}$ e fotoperíodo de 16 horas. $\mathrm{O}$ número de repetições/tratamento foi igual a três (ou duas, quando houve perda por contaminação). Aos 28 dias, foi avaliado o número médio de brotos por explante por tratamento hormonal, procedendo-se a uma ANOVA em esquema fatorial ( 4 x 5). Avaliou-se também a porcentagem de explantes com regeneração.

\section{Linhagens de Agrobacterium e vetor de transferência}

Foram usadas sete linhagens selvagens para testar a suscetibilidade do Stylosanthes ao Agrobacterium (Tabela 1). Nos ensaios para avaliar a expressão transiente do gene uidA, foram utilizadas as linhagens desarmadas 
GV2260 (Deblaere et al., 1985) e GV3101 (Koncz \& Schell, 1986), ambas derivadas da linhagem selvagem C58 e transformadas com o vetor pEA24, que contém o gene uidA ( $\beta$-glucuronidase) sob controle do promotor 35S. Esse vetor foi cedido ao Departamento de Genética da ESALQ-USP pela Embrapa-Centro Nacional de Pesquisa de Recursos Genéticos e Biotecnologia.

\section{Crescimento das bactérias e infecção dos explantes com linhagens selvagens}

Uma colônia de Agrobacterium foi transferida para $10 \mathrm{~mL}$ de meio MYA (Tepfer \& Casse-Delbart, 1987) e cultivada por 16 horas em mesa agitadora orbital (150 rpm), à temperatura $26 \pm 2^{\circ} \mathrm{C}$. Uma alíquota de $1 \mathrm{~mL}$ foi transferida para meio fresco, permanecendo nas mesmas condições por seis horas, até atingir a densidade ótica de $0,8-1,0$ a $660 \mathrm{~nm}$ (Mathis \& Hinchee, 1994). A subcultura foi então centrifugada a $4.000 \mathrm{rpm}$, por oito minutos. O precipitado foi ressuspenso em $\mathrm{NaCl} 0,85 \%(\mathrm{p} / \mathrm{v})$ contendo $40 \mu \mathrm{M}$ de acetosyringone, ajustando a concentração final para $1 \times 10^{9}$ bactérias $/ \mathrm{mL}$. A suspensão foi coletada em seringa esterilizada e usada para ferir o terço superior dos hipocótilos em ambos os lados, resultando em dez ferimentos/explante. Nesta etapa foi usada somente a cv. Bandeirantes.

\section{Infecçãodos explantes no ensaio da enzima B-glucuronidase (uidA)}

Foram inoculados de 15 a 20 explantes hipocotiledonares, em frascos $(120 \mathrm{~mL})$ contendo $5 \mathrm{~mL}$ de suspensão bacteriana, obtida conforme descrito anteriormente, porém substituindo $\mathrm{NaCl} 0,85 \%$ por MS líquido. Os frascos foram agitados a $60 \mathrm{rpm}$, por quatro a seis horas. Os explantes foram então transferidos para placas de Petri $(9 \mathrm{~cm})$ contendo meio MS, no qual permaneceram em co-cultivo por 48 horas, a $26^{\circ} \mathrm{C}$. O excesso de meio líquido foi retirado dos explantes com papel filtro antes da transferência para meio sólido. O co-cultivo foi interrompido por duas lavagens dos explantes em solução de tetraciclina (50 mg L $\mathrm{m}^{-1}$ ), sob agitação a $160 \mathrm{rpm}$, por 30 minutos, seguidas de uma lavagem em água destilada e autoclavada (15 a 20 explantes $/ 50 \mathrm{~mL}$ ). Os explantes derivados da região superior dos hipocótilos da cv. Mineirão foram transferidos para $\mathrm{MS}+0,1 \mathrm{mg} \mathrm{L}^{-1}$ de BAP, enquanto os da região inferior foram transferidos para $\mathrm{MS}+0,1 \mathrm{mg} \mathrm{L}^{-1} \mathrm{de}$ $\mathrm{NAA}+0,5 \mathrm{mg} \mathrm{L}^{-1}$ de BAP. Ambos os explantes da cv. Bandeirantes foram transferidos para $\mathrm{MS}+0,5 \mathrm{mg} \mathrm{L}^{-1}$ de BAP.

Para verificar a eficiência dos procedimentos de transformação adotados, foram realizados ensaios de expressão transiente do gene uidA, 48 horas após o término do co-cultivo. Os explantes foram colocados em tubo eppendorf e cobertos com $1 \mathrm{~mL}$ da solução composta de $1 \mathrm{mM}$ de X-Gluc dissolvido em tampão $100 \mathrm{mM} \mathrm{NaPO}_{4}$, $\mathrm{pH} 7,0 ; 10 \mathrm{mM}$ EDTA, $\mathrm{pH} 7,0 ; 0,5 \mathrm{mM}$ ferrocianeto de potássio; $0,5 \mathrm{mM}$ ferricianeto de potássio e $0,1 \%$ Triton-X. Os tubos eppendorf foram colocados em banho-maria a $37^{\circ} \mathrm{C}$, por 24 horas. Em seguida, a solução foi substituída por etanol $70 \%(\mathrm{v} / \mathrm{v})$, para descoloração dos explantes (Stomp, 1992).

\section{Efeito dos antibióticos cefotaxima e tetraciclina}

Explantes excisados da região superior e inferior do hipocótilo das cvs. Bandeirantes e Mineirão foram submetidos aos seguintes tratamentos: i) controle: os explantes foram infectados em meio MS, livre de fitorreguladores, durante 48 horas, simulando o co-cultivo, e então transferidos para meio de regeneração, como descrito no ensaio de uidA; ii) tetraciclina: semelhante ao controle, porém antes da transferência para meio de regeneração foram efetuadas três lavagens em solução de tetraciclina a $50 \mu \mathrm{g} \mathrm{mL}-1$; iii) cefotaxima: semelhante ao controle, porém ao meio de regeneração foram adicionados $250 \mu \mathrm{g} \mathrm{mL}^{-1}$ de cefotaxima, sendo que para a cv. Bandeirantes foi também avaliada a concentração de $100 \mu \mathrm{g} \mathrm{mL} \mathrm{m}^{-1}$. Os dados relativos à freqüência de regeneração e número médio de brotos/explante foram coletados aos 28 dias.

TABELA 1. Linhagens selvagens de Agrobacterium usadas e sua classificação por tipo de opina sintetizada.

\begin{tabular}{llll}
\hline Linhagem & Espécie & Opina & Referência \\
\hline B6S3 & A.tumefaciens & Octopina & Benetka \& Pavingerová (1995) \\
A208 & A.tumefaciens & Nopalina, agropina & Montoya et al. (1977) \\
C58 & A.tumefaciens & Nopalina & Broer et al. (1995) \\
T37 & A.tumefaciens & Nopalina & Salem \& Charlwood (1995) \\
8196 & A. rhizogenes & Manopina & Petit et al. (1983) \\
A4 & A.rhizogenes & Agropina & Gaudin \& Jouanin (1995) \\
A4T & A. rhizogenes & Nopalina, agropina & Golds et al.(1991) \\
\hline
\end{tabular}




\section{RESULTADOS E DISCUSSÃO}

As sementes da cv. Mineirão, escarificadas manualmente, apresentaram entumescimento e formação de calo na base dos hipocótilos, quando germinadas em MS/2. A partir desta observação, as sementes passaram a ser germinadas em MS/6, gerando explantes para os experimentos de cultura de tecidos. Sementes escarificadas pelo processo térmico forneceram explantes normais, em MS/2 ou $\mathrm{MS} / 6$.

O número médio de brotos regenerados por explante, em cada tratamento, está apresentado nas Tabelas 2 e 3 . Foi mais uma vez comprovada a eficiência do fitorregulador BAP na formação de brotos, via organogênese, como é usual nas diferentes

TABELA 2. Número médio de brotos desenvolvidos a partir de explantes derivados da região superior e inferior do hipocótilo, folíolo, cotilédone e raiz de Stylosanthes guianensis cv. Bandeirantes, em diferentes doses de NAA e BAP $\left(\mathrm{em} \mathrm{mg} \mathrm{L}^{-1}\right)^{1}$.

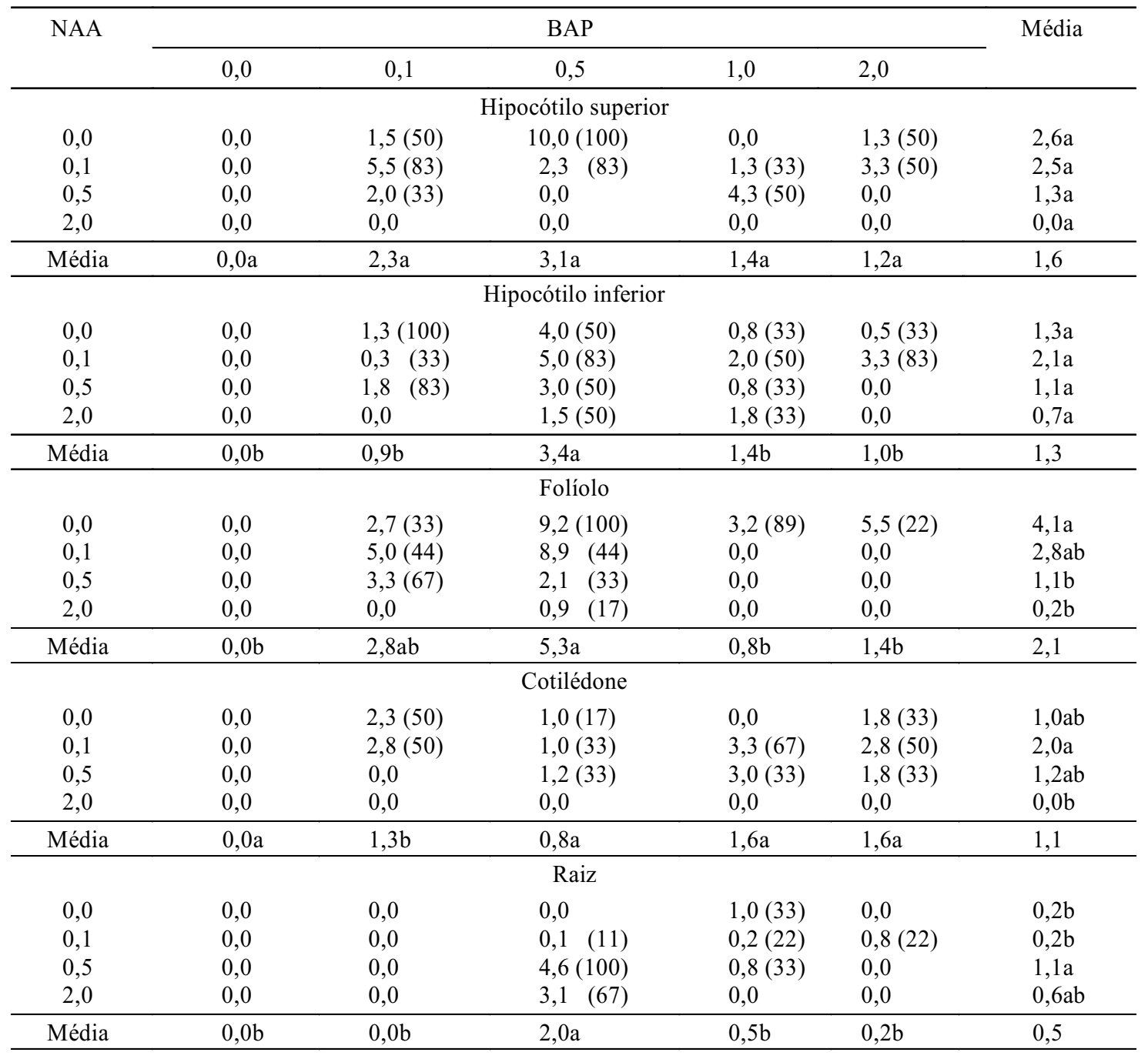

${ }^{1}$ Médias seguidas da mesma letra não diferem estatisticamente, segundo o teste de Tukey, a $5 \%$ de probabilidade; quando diferente de zero, a porcentagem de explantes que produziram brotos está entre parênteses. 
espécies de Stylosanthes (Vieira et al., 1990; Meijer \& Szabados, 1991). As freqüências de regeneração, avaliadas pela porcentagem de explantes com gemas, foram semelhantes ou superiores às relatadas com relação a $S$. guianensis por Meijer \& Broughton (1981) e Mesa et al. (1993).

Em meio MS, na ausência de reguladores de crescimento, explantes derivados de cotilédones e folíolos, de ambas as cultivares, apresentaram rizogênese, provavelmente devido à presença de auxina endógena. Os cinco tipos de explante das duas cultivares apresentaram rizogênese na dose zero de BAP quando na presença de NAA, em qualquer dose.

Em geral, não foi observada regeneração da parte aérea na ausência de reguladores de crescimento.

TABELA 3. Número médio de brotos desenvolvidos a partir de explantes derivados da região superior e inferior do hipocótilo, folíolo, cotilédone e raiz de Stylosanthes guianensis cv. Mineirão, em diferentes doses de NAA e BAP (em mg L $\left.{ }^{-1}\right)^{1}$.

\begin{tabular}{|c|c|c|c|c|c|c|}
\hline \multirow[t]{2}{*}{ NAA } & \multicolumn{5}{|c|}{ BAP } & \multirow[t]{2}{*}{ Média } \\
\hline & 0,0 & 0,1 & 0,5 & 1,0 & 2,0 & \\
\hline \multicolumn{7}{|c|}{ Hipocótilo superior } \\
\hline 0,0 & $5,0(33)$ & $20,0(100)$ & $15,0(100)$ & $13,3(100)$ & $6,7(67)$ & $12,0 \mathrm{a}$ \\
\hline 0,1 & 0,0 & $13,3 \quad(67)$ & $10,0 \quad(67)$ & $1,7 \quad(33)$ & 0,0 & $5,0 \mathrm{a}$ \\
\hline 0,5 & 0,0 & $2,7 \quad(67)$ & $0,7 \quad(33)$ & 0,0 & 0,0 & $0,7 b$ \\
\hline 2,0 & 0,0 & 0,0 & $1,0 \quad(33)$ & 0,0 & 0,0 & $0,2 b$ \\
\hline Média & $1,3 \mathrm{~b}$ & $9,0 \mathrm{a}$ & $6,7 \mathrm{ab}$ & $3,8 \mathrm{ab}$ & $1,7 \mathrm{~b}$ & 4,5 \\
\hline \multicolumn{7}{|c|}{ Hipocótilo inferior } \\
\hline 0,0 & $1,3(33)$ & $9,3(100)$ & $10,7(100)$ & $5,0(100)$ & $4,3 \quad(67)$ & $6,1 \mathrm{a}$ \\
\hline 0,1 & 0,0 & $2,0 \quad(33)$ & $16,7(100)$ & 0,0 & $1,7(100)$ & $4,1 \mathrm{a}$ \\
\hline 0,5 & 0,0 & 0,0 & $1,0 \quad(67)$ & $7,0 \quad(67)$ & 0,0 & $1,6 \mathrm{a}$ \\
\hline 2,0 & 0,0 & 0,0 & 0,0 & 0,0 & 0,0 & $0,0 \mathrm{a}$ \\
\hline Média & $0,4 a$ & $3,8 \mathrm{a}$ & $7,1 \mathrm{a}$ & $3,0 \mathrm{a}$ & $1,5 \mathrm{a}$ & 3,0 \\
\hline \multicolumn{7}{|c|}{ Folíolo } \\
\hline 0,0 & 0,0 & 0,0 & 0,0 & $1,5 \quad(33)$ & 0,0 & $0,3 \mathrm{a}$ \\
\hline 0,1 & 0,0 & 0,0 & 0,0 & 0,0 & 0,0 & $0,0 \mathrm{a}$ \\
\hline 0,5 & 0,0 & 0,0 & 0,0 & 0,0 & 0,0 & $0,0 \mathrm{a}$ \\
\hline 2,0 & 0,0 & 0,0 & 0,0 & $2,0(100)$ & 0,0 & $0,4 \mathrm{a}$ \\
\hline Média & $0,0 \mathrm{~b}$ & $0,0 \mathrm{~b}$ & $0,0 \mathrm{ba}$ & $0,9 a$ & $0,0 \mathrm{~b}$ & 0,2 \\
\hline \multicolumn{7}{|c|}{ Cotilédone } \\
\hline 0,0 & 0,0 & $1,3(33)$ & $3,0(33)$ & $1,0(33)$ & 0,0 & $1,1 \mathrm{a}$ \\
\hline 0,1 & 0,0 & $2,8(67)$ & $0,8(33)$ & $1,3(33)$ & 0,0 & $1,0 \mathrm{a}$ \\
\hline 0,5 & 0,0 & 0,0 & $3,0(33)$ & 0,0 & 0,3 (17) & $0,7 \mathrm{a}$ \\
\hline 2,0 & 0,0 & 0,0 & $1,3(33)$ & 0,0 & $1,8(33)$ & $0,6 a$ \\
\hline Média & $0,0 \mathrm{~b}$ & $1,0 \mathrm{ab}$ & $2,0 \mathrm{a}$ & $0,6 a b$ & $0,5 \mathrm{ab}$ & 0,8 \\
\hline \multicolumn{7}{|c|}{ Raiz } \\
\hline 0,0 & $0,7(17)$ & $1,0(17)$ & 0,0 & $0,2(17)$ & $2,7(100)$ & $0,9 \mathrm{ab}$ \\
\hline 0,1 & 0,0 & 0,2 (17) & $2,5(67)$ & 0,8 (17) & $1,3 \quad(67)$ & $1,0 \mathrm{a}$ \\
\hline 0,5 & 0,0 & 0,0 & 0,0 & 0,0 & $0,2 \quad(67)$ & $0,0 \mathrm{~b}$ \\
\hline 2,0 & 0,0 & 0,0 & 0,0 & 0,0 & 0,0 & $0,0 \mathrm{~b}$ \\
\hline Média & $0,2 a$ & $0,3 a$ & $0,6 \mathrm{a}$ & $0,3 a$ & $1,1 \mathrm{a}$ & 0,5 \\
\hline
\end{tabular}

${ }^{1}$ Médias seguidas da mesma letra não diferem estatisticamente, segundo o teste de Tukey, a $5 \%$ de probabilidade; quando diferente de zero, a porcentagem de explantes que produziram brotos está entre parênteses. 
Porém, explantes derivados de raiz e hipocótilo (segmento superior ou inferior) da cv. Mineirão apresentaram regeneração de brotos nesta condição. Nos demais explantes, a adição de BAP, combinada, ou não, com NAA, provocou aparecimento de brotos.

Os explantes derivados de folha foram os mais recalcitrantes em cultura, em ambas as cultivares. Ao contrário, os explantes hipocotiledonares foram os que responderam ao maior número de combinações de fitorreguladores (Tabelas 2 e 3). Na cv. Mineirão, explantes hipocotiledonares deram origem, em média, a 20,0 (segmento superior) e 16,7 (segmento inferior) brotos por explante, na presença de $\mathrm{MS}+0,1 \mathrm{mg} \mathrm{L}^{-1}$ de BAP e MS + 0,1 mg L $\mathrm{me}^{-1} \mathrm{de}$ $\mathrm{NAA}+0,5 \mathrm{mg} \mathrm{L}^{-1}$ de BAP, respectivamente (Fig. 1a). Explantes hipocotiledonares foram igualmente responsivos em $S$. humilis (Meijer, 1982), S. scabra (Dornelas et al., 1991) e S. guianensis (Mesa et al., 1993).

A exemplo do que tem sido relatado na literatura (Dornelas et al.,1991; Meijer \& Szabados, 1991; Silva, 1991), a regeneração de brotos se deu mediada por calo. Houve formação de brotos adventícios, sem passagem por calo conspícuo, a partir de explantes cotiledonares e hipocotiledonares, em ambas as cultivares. Esta resposta foi observada nos explantes cotiledonares da cv. Bandeirantes em MS $+0,1 \mathrm{mg} \mathrm{L}^{-1}$ de BAP ou suplementado com $0,1 \mathrm{mg} \mathrm{L}^{-1}$ de NAA e $0,1 \mathrm{mg} \mathrm{L}^{-1}$ de BAP e a partir de explantes hipocotiledonares inoculados em MS $+0,5 \mathrm{mg} \mathrm{L}^{-1}$ de BAP (Tabela 2).

$\mathrm{Na}$ cv. Mineirão, a adição isolada de 0,1 ou $0,5 \mathrm{mg} \mathrm{L}^{-1}$ de BAP possibilitou a formação de brotos adventícios em 100\% dos explantes hipocotiledonares (superiores); o mesmo foi observado em $\mathrm{MS}+0,1 \mathrm{mg} \mathrm{L}^{-1}$ de NAA $+0,5 \mathrm{mg} \mathrm{L}^{-1}$ de BAP quanto a explantes derivados da região inferior dos hipocótilos dessa cultivar (Tabela 3 ). A regeneração sem passagem por calo conspícuo é desejada em cultura de tecidos, uma vez que desfavorece a incidência de variação somaclonal, que deve ser evitada quando se visa à transformação genética.

$\mathrm{O}$ aparecimento das primeiras gemas foi observado aos 21 dias de cultura, em todos os explantes da cv. Bandeirantes e nos cotilédones da cv. Mineirão. Em explantes derivados de hipocótilos e raízes da cv. Mineirão, a regeneração ocorreu mais precocemente, aos 14 dias, e em explantes derivados de folíolo, mais tarde, aos 28 dias de cultura.
As combinações hormonais que induziram maior número médio de brotos por explante foram aquelas nas quais houve $100 \%$ de regeneração, exceto em explantes oriundos dos hipocótilos inferiores da cv. Bandeirantes. Na combinação $\mathrm{MS}+0,1 \mathrm{mg} \mathrm{L}^{-1} \mathrm{de}$ $\mathrm{NAA}+0,5 \mathrm{mg} \mathrm{L}^{-1}$ de BAP, 83,3\% dos explantes mostraram regeneração, e cinco brotos por explante, em média, foram observados (Tabela 2).

Nos explantes infectados com as várias linhagens selvagens de Agrobacterium tumefaciens observouse a formação de tumores (Fig. 1b), os quais não ocorreram nos tecidos controle (Tabela 4). No caso $\mathrm{da}$ infecção com linhagens selvagens de A. rhizogenes, observou-se igualmente a formação de tumores e de raízes em cabeleira (Weising \& Kahl, 1996). É possível que esse sintoma se deva à ação combinada dos genes iaaM e iaaH, presentes no plasmídeo $\mathrm{R}_{\mathrm{i}}$, com o teor endógeno de citocinina dos explantes infectados.

As linhagens A208 e 8196 foram superiores quanto à capacidade de induzir a formação de tumores (ensaio A). Da mesma forma, as linhagens A4 e $\mathrm{A} 4 \mathrm{~T}$, esta na presença, ou não, de $40 \mu \mathrm{M}$ de acetosyringone, mostraram-se superiores (ensaio B). A infecção do tecido vegetal com a linhagem C58 (40 $\mu \mathrm{M}$ de acetosyringone) induziu a maior formação de brotos por explante (Tabela 4 ).

O aparecimento de brotos adventícios nos locais de ferimento foi observado cerca de 20 dias após o ferimento dos explantes com seringa contendo a cultura de Agrobacterium selvagem. Esses brotos surgiram também nos controles. A formação espontânea de brotos nos locais de ferimento foi igualmente relatada em plantas transformadas com o gene ipt de A. tumefaciens, que induz superexpressão de citocininas (Binns, 1994). Essa tendência foi observada por Gloria \& Estelita (1995), em espécies brasileiras de cerrado, Mandevilla illustris e M. velutina.

Os brotos formados a partir dos explantes infectados com linhagens selvagens puderam ser excisados e mantidos livres de contaminação pelo Agrobacterium (os inóculos permaneceram restritos à região de ferimento). Cerca de $22 \%$ deles (oriundos de explantes infectados com a linhagem A4) apresentaram formação de calo e raízes na parte aérea, alterações essas semelhantes às causadas pela ação de oncogenes (Fig. 1c). A brotação induzida diretamente pela infecção de tecidos vegetais com linha- 


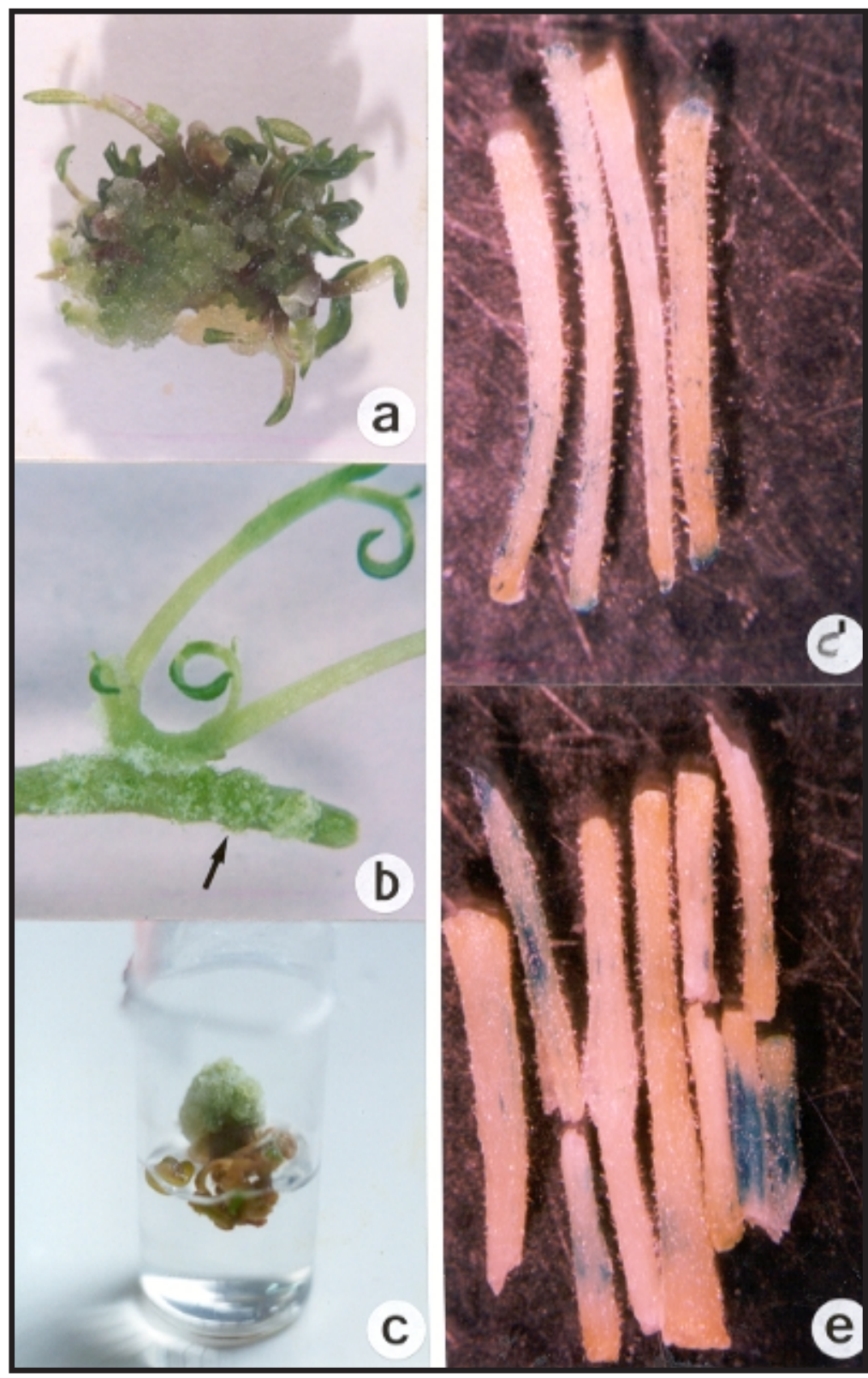

FIG. 1. Regeneração de brotos da cv. Mineirão em explantes derivados da região superior dos hipocótilos, inoculados em $\mathrm{MS}+0,1 \mathrm{mg} \mathrm{L}^{-1} \mathrm{de}$ NAA + 0,5 $\mathrm{mg} \mathrm{L}^{-1}$ de BAP, aos 28 dias de cultura (a); resposta de explantes hipocotiledonares da cv. Bandeirantes à infecção com a linhagem 8196 de Agrobacterium selvagem, mostrando a formação de tumores e brotos (b) e tumor desenvolvido na superfície de uma plântula, oriunda de um explante previamente infectado com a linhagem A4 (c); expressão transiente do gene uidA em explantes hipocotiledonares das cvs. Mineirão (d) e Bandeirantes (e). 
TABELA4. Número médio de tumores desenvolvidos (Tumor) e brotos diferenciados (broto/explante) em dois ensaios de infecção de hipocótilos da cv. Bandeirantes com linhagens selvagens de Agrobacterium.

\begin{tabular}{clrcc}
\hline Ensaio Linhagem & $\mathrm{n}^{1}$ & Tumor & $\begin{array}{c}\text { Broto/ } \\
\text { explante }\end{array}$ \\
\hline A & Controle & 20 & $0,00 \pm 0,00$ & $1,10 \pm 0,29$ \\
& T37 & 13 & $1,69 \pm 0,69^{*}$ & $1,38 \pm 0,55$ \\
& B6S3 & 9 & $1,89 \pm 0,73$ & $1,11 \pm 0,59$ \\
& A208 & 18 & $3,89 \pm 0,73^{*}$ & $1,33 \pm 0,46$ \\
& 8196 & 21 & $3,19 \pm 0,56^{*}$ & $1,95 \pm 0,48$ \\
B & Controle & 36 & $0,00 \pm 0,00$ & $1,80 \pm 0,39$ \\
& Controle-asy & 40 & $0,00 \pm 0,00$ & $2,30 \pm 0,33$ \\
& A4 & 8 & $1,25 \pm 0,56 *$ & $4,50 \pm 1,17$ \\
& A4-asy & 6 & $0,83 \pm 0,83$ & $3,33 \pm 1,15$ \\
& C58 & 9 & $0,33 \pm 0,33$ & $1,00 \pm 0,55$ \\
& C58-asy & 20 & $0,40 \pm 0,17$ & $3,55 \pm 0,51^{*}$ \\
& A4T & 10 & $1,20 \pm 0,59^{*}$ & $0,60 \pm 0,27$ \\
A4T-asy & 20 & $0,75 \pm 0,24^{*}$ & $2,45 \pm 0,65$ \\
\hline
\end{tabular}

1 Número de explantes inoculados.

2 Acetosyringone $40 \mu \mathrm{M}$

* Difere dos controles, segundo teste estatístico não-paramétrico de Kruskal-Wallis, a $5 \%$ de probabilidade. gens selvagens de Agrobacterium tem sido apontada como vantajosa em relação aos métodos usuais de transferência de genes, que requerem passagem por cultura e o uso de antibióticos (Brasileiro et al., 1991). Além disso, estudos histológicos têm mostrado que uma das limitações da metodologia de transformação mediada pelo Agrobacterium é obter células transformadas com capacidade de regeneração de brotos.

Explantes derivados de hipocótilos mostraram pontos azuis resultantes da expressão do gene uidA (Fig. 1d-e). A freqüência de explantes uidA-positivos foi de $100 \%$ na cv. Bandeirantes e de $91 \%$ na cv. Mineirão.

Os explantes tratados com tetraciclina ou cefotaxima foram comparados aos controles, com o objetivo de verificar se estes antibióticos são prejudiciais à regeneração. Não foram detectadas diferenças significativas no que se refere às porcentagens de regeneração e número médio de brotos por explante, aos 28 dias de cultura, em todos os tratamentos (Tabela 5). A lavagem em tetraciclina é auxiliar na eliminação das bactérias. Embora não signi-

TABELA 5. Regeneração de brotos (Broto) e número médio de brotos diferenciados a partir da região superior (HS) e inferior (HI) dos hipocótilos (Broto/Explante), segundo o tratamento e a cv. de Stylosanthes guianensis.

\begin{tabular}{llllcc}
\hline Cultivar & Tratamento & Explante & $\mathrm{n}^{1}$ & $\begin{array}{c}\text { Broto } \\
(\%)\end{array}$ & $\begin{array}{c}\text { Broto/ }^{2} \\
\text { explante }^{2}\end{array}$ \\
\hline Bandeirantes & Controle & HS & 3 & 66 & 2,0 \\
& Tetraciclina & HI & 3 & 66 & 4,7 \\
& Cefotaxima & HS & 3 & 66 & 9,7 \\
& $250 \mu \mathrm{g} \mathrm{mL}^{-1}$ & HS & 3 & 66 & 1,0 \\
& Controle & HI & 3 & 0 & 0,0 \\
& Tetraciclina & HS & 10 & 0 & 2,0 \\
& & HI & 10 & 80 & 3,2 \\
& Cefotaxima & HI & 10 & 70 & 3,5 \\
& $100 \mu \mathrm{gL} \mathrm{mL}^{-1}$ & HS & 10 & 40 & 1,4 \\
& Controle & HI & 10 & 60 & 0,3 \\
\hline Mineirão & HS & 10 & 40 & 7,0 \\
& Tetraciclina & HI & 10 & 60 & 5,7 \\
& Cefotaxima & HI & 10 & 90 & 7,8 \\
& 250 $\mu \mathrm{gL} \mathrm{mL}^{-1}$ & HS & 10 & 70 & 8,0 \\
& HI & 10 & 70 & 6,7 \\
& & 10 & 70 & 4,1 \\
\hline
\end{tabular}

1 Número de explantes infectados.

${ }^{2}$ F não-significativo em todos os tratamentos $\left(\mathrm{P}=0,14\right.$, cv. Bandeirantes, cefotaxima $250 \mu \mathrm{g} \mathrm{mL}^{-1} ; \mathrm{P}=0,14$, cv. Bandeirantes, cefotaxima $100 \mu \mathrm{g} \mathrm{mL}^{-1}$; $\mathrm{P}=0,57$, cv. Mineirão, cefotaxima $\left.250 \mu \mathrm{g} \mathrm{mL}^{-1}\right)$. 
ficativo, o tratamento com cefotaxima a $250 \mu \mathrm{g} \mathrm{mL}-1$ reduziu as freqüências de regeneração a zero $(\mathrm{P}=0,14)$ em explantes hipocotiledonares da cv. Bandeirantes. Por isso, recomenda-se a dose de $100 \mu \mathrm{g} \mathrm{mL}^{-1}$. A cv. Mineirão mostrou-se tolerante à presença da cefotaxima (Tabela 5).

A cefotaxima atua em cultura de modo similar a uma auxina (Sarma et al., 1995), e sua toxicidade pode ser atribuída a este efeito (Lin et al., 1995). Aparentemente, devem-se a essa ação a formação mais conspícua de calo e a redução da capacidade de regeneração de brotos, observadas na cv. Bandeirantes.

\section{CONCLUSÕES}

1. As cultivares Bandeirantes e Mineirão de Stylosanthes guianensis mostram regeneração de brotos adventícios a partir da cultura de explantes hipocotiledonares em meio suplementado com BAP.

2. O Stylosanthes guianensis é suscetível à infecção por linhagens selvagens e transformadas de Agrobacterium.

3. A lavagem em tetraciclina não prejudica o desenvolvimento dos explantes de Stylosanthes guianensis em cultura, e é auxiliar na eliminação do Agrobacterium.

4. A adição do antibiótico cefotaxima na dose $250 \mu \mathrm{g} \mathrm{mL}^{-1}$ causa redução na capacidade de regeneração em explantes da cv. Bandeirantes, porém é tolerada pela cv. Mineirão.

\section{AGRADECIMENTOS}

Ao biólogo Carlos Alberto de Oliveira, pelo apoio técnico; ao M.Sc. Luciano Cônsoli, pelas sugestões durante a condução dos ensaios de transformação; aos pesquisadores da Embrapa, M.Sc. Claudio Karia (Embrapa-CPAC) e Dr. Eugen Gander (EmbrapaCenargen), pela cessão das sementes de Stylosanthes e do vetor pEA24, respectivamente.

\section{REFERÊNCIAS}

BARROS, L.M.G.; GAMA, M.I.C.S.; GONÇALVES, C.H.R. de P.; BARRETO, C.C.; SANTANA, E.F.; CARNEIRO, V.T. de C. Cultura de tecidos de feijoeiro visando à introdução de genes exógenos. Pesquisa Agropecuária Brasileira, Brasília, v.32, n.3, p.267-275, mar. 1997.
BenetKA, V.; PAVIngerovÁ, D. Phenotypic differences in transgenic plants of chrysanthemum. Plant Breeding, Berlin, v.114, p.169-173, 1995.

BINNS, A. Cytokinin accumulation and action: biochemical, genetic and molecular approaches. Annual Review of Plant Physiology and Plant Molecular Biology, Palo Alto, v.45, p.173-196, 1994.

BRASILEIRO, A.C.M.; LEPLE, J.C.; MUZZIN, J.; OUNNOUGHI, D.; MICHEL, M.; JOUANIN, L. An alternative approach for gene transfer in trees using wild-type Agrobacterium strains. Plant Molecular Biology, Dordrecht, v.17, n.3, p.441-452, 1991.

BROER, I.; DRÖGE-LASER, W.; BARKER, R.F.; NEUMANN, K.; KLIPP, W.; PÜHLER, A. Identification of the Agrobacterium tumefaciens C58 T-DNA genes $e$ and $f$ and their impact on crown gall tumor formation. Plant Molecular Biology, Dordrecht, v.27, p.41-57, 1995.

DEBLAERE, R.; BYTEBIER, B.; GREVE, H. de; DEBOECK, F.; SHELL, J.; MONTAGU, M. van; LEEMANS, J. Efficient octopine Ti plasmid-derived vectors for Agrobacterium-mediated gene transfer to plants. Nucleic Acids Research, Oxford, v.13, p.4777-4789, 1985.

DORNELAS, M.C.; VIEIRA, M.L.C.; GLORIA, B.A. da. Histological analysis of organogenesis and somatic embryogenesis induced in immature tissues of Stylosanthes scabra. Annals of Botany, London, v.70, p.477-482, 1992.

DORNELAS, M.C.; VIEIRA, M.L.C.; SOUZA JUNIOR, C.L. de. Fonte e idade de explante, radiação luminosa e combinações de NAA e BAP na indução de calos em Stylosanthes scabra Vog. Pesquisa Agropecuária Brasileira, Brasília, v.26, n.11/12, p.1901-1909, nov./dez. 1991.

EMBRAPA. Centro de Pesquisa Agropecuária dos Cerrados (Planaltina, DF). Recomendações para estabelecimento e utilização do Stylosanthes guianensis cv. Minerão. Planaltina : Embrapa-CPAC/ Campo Grande : Embrapa-CNPGC, 1993. 6p. (Embrapa-CPAC. Comunicado Técnico, 67; Embrapa-CNPGC. Comunicado Técnico, 49).

GAUDIN, V.; JOUANIN, L. Expression of Agrobacterium rhizogenes auxin biosynthesis genes in transgenic tobacco plants. Plant Molecular Biology, Dordrecht, v.28, p.123-136, 1995.

Pesq. agropec. bras., Brasília, v.35, n.4, p.733-742, abr. 2000 
GHISI, O.M.A.; ALMEIDA, A.R.P.; ALCANTARA, V.B.; SANCHEZ, M.J.F.; MECELIS, N.R. Estudo morfológico e agronômico de quatro acessos de Stylosanthes guianensis sob três alturas de corte e sob pastejo animal. Boletim de Indústria Animal, Nova Odessa, v.50, p.69-78, 1993.

GLORIA, B.A. da; ESTELITA, M.E.M. Caracteres anatômicos da propagação vegetativa de Mandevilla illustris (Vell.) Woodson e de M. velutina (Mart. ex Stadelm.) Woodson-Apocynaceae. In: CONGRESSO DA SOCIEDADE BOTÂNICA DE SÃO PAULO, 9., 1992, Ilhabela. Anais. São Paulo : Sociedade Botânica de São Paulo, 1995. p.5-13.

GOLDS, T.J.; LEE, J.Y.; HUSNAIN, T.; GHOSE, T.K.; DAVEY, M.R. Agrobacterium rhizogenes mediated transformations of the forage legumes Medicago sativa and Onobrychis viciifolia. Journal of Experimental Botany, Oxford, v.42, p.1147-1157, 1991.

HOPKINSON, J.M.; WALKER, B. Seed production of Stylosanthes cultivars in Australia. In: STACE, H.M.; EDYE, L.A. (Eds.). The biology and agronomy of Stylosanthes. Sydney : Academic, 1984. p.433-450.

KONCZ, C.; SCHELL, J. The promoter of $T_{L}$-DNA gene 5 controls the tissue-specific expression of chimaeric genes carried by a novel type of Agrobacterium binary vector. Molecular and General Genetics, Berlin, v.204, p.383-386, 1986.

LIN, J.; ASSAD-GARCIA, N.; KUO, J. Plant hormone effect of antibiotics on the transformation efficiency of plant tissues by Agrobacterium tumefaciens cells. Plant Science, Limerick, v.109, p.171-177, 1995.

MATHIS, N.L.; HINCHEE, M.A.W. Agrobacterium inoculation technics for plant tissues. In: GELVIN, S.B.; SCHILPEROORT, R.A. (Eds.). Plant molecular biology manual. 2.ed. Dordrecht : Kluwer Academic, 1994. p.B6/1-9.

MEIJER, E.G. High-frequency plant regeneration from hypocotyl- and leaf-derived tissue cultures of the tropical pasture legume Stylosanthes humilis. Physiologia Plantarum, Copenhagen, v.56, p.381-385, 1982.

MEIJER, E.G.M.; BROUGHTON, W.J. Regeneration of whole plants from hypocotyl-, root-, and leaf-derived tissue cultures of the pasture legume Stylosanthes guianensis. Physiologia Plantarum, Copenhagen, v.52, p.280-284, 1981.

MEIJER, E.G.M.; SZABADOS, L. Cell and tissue culture of Stylosanthes spp. In: BAJAJ, Y.P.S. (Ed.). Biotechnology in agriculture and forestry. London : Springer, 1991. v.10, p.313-321.
MESA, A.R.; LAJONCHERE, G.; PRIETO, M.; TORAL, O. Organogenesis en Stylosanthes guianensis cv. CIAT 184. Pastos y Forrajes, Matanzas, v.16, p.207-210, 1993.

MONTOYA, A.L.; CHILTON, M.D.; GORDON, M.P.; SCIAKY, D.; NESTER, E.W. Octopine and nopaline metabolism in Agrobacterium tumefaciens and crown gall tumor cells: role of plasmid genes. Journal of Bacteriology, Washington, n.129, p.101-107, 1977.

MURASHIGE, T.; SKOOG, F. A revised medium for rapid growth and bioassays with tobacco tissue cultures. Physiologia Plantarum, Copenhagen, v.15, p.473-497, 1962.

PETIT, A.; DAVID, C.; DAHL, G.A.; ELLIS, J.G.; GUYON, P. Further extension of the opine concept: plasmids in Agrobacterium rhizogenes cooperate for opine degradation. Molecular and General Genetics, Berlin, v.190, p.204-214, 1983.

SALEM, K.M.S.A.; CHARLWOOD, B.V. Accumulation of essential oils by Agrobacterium tumefaciens transformed shoot cultures of Pimpinella anisum. Plant Cell, Tissue and Organ Culture, Dordrecht, v.40, p.209-215, 1995.

SARMA, K.S.; EVANS, N.E.; SELBY, C. Effect of carbenicillin and cefotaxime on somatic embryogenesis of Sitka spruce (Picea sitchensis Bong.) Carr. Journal of Experimental Botany, Oxford, v.46, p.1779-1781, 1995.

SILVA, B.A. Cultura de tecidos de Stylosanthes guianensis (Aubl.) Sw. Cv. IRI 1022: estudo morfogenético e histológico. Piracicaba : ESALQ, 1991. 168p. Dissertação de Mestrado.

STOMP, A.M. Histochemical localization of b-glucuronidase. In: GALLAGHER, S.R. (Ed.). GUS protocols: using the GUS gene as a reporter of gene expression. San Diego : Academic, 1992. p.103-113.

TEPFER, M.; CASSE-DELBART, F. Agrobacterium rhizogenes as a vector for transforming higher plants. Microbiological Sciences, Oxford, v.4, p.24-28, 1987.

VIEIRA, M.L.C.; JONES, B.; COCKING, E.C.; DAVEY, M.R. Plant regeneration from protoplasts isolated from seedling cotyledons of Stylosanthes guianensis, S. macrocephala and S. scabra. Plant Cell Reports, Berlin, v.9, p.289-292, 1990.

WEISING, K.; KAHL, G. Natural genetic engineering of plant cells: the molecular biology of crown gall and hairy root disease. World Journal of Microbiology \& Biotechnology, Oxford, v.12, p.27-51, 1996. 